\title{
Prompt, Aggressive BP Lowering in High-Risk Patients
}

\author{
Kenneth A. Jamerson, $M D^{\prime}{ }^{1}$ Jan Basile, $M D^{2,3}$
}

Various populations with hypertension have been singled out by current treatment guidelines as requiring more specific treatment. These include patients with stage 2 bypertension, black patients, and patients with coexistent diabetes mellitus and coronary heart disease. Hypertension in these groups is often associated with higher risk of cardiovascular morbidity and mortality. This article reviews current knowledge regarding hypertension in high-risk patient populations, with a particular focus on the importance of prompt, aggressive treatment to lower blood pressure and prevent cardiovascular disease progression. Such treatment includes the early use of multiple-drug therapy with agents that have complementary blood pressure-lowering mechanisms and provide protection from target organ damage. While 2- or 3-drug antihypertensive therapy in these high-risk groups has typically included a diuretic, other combinations of agents may be indicated. Evidence suggests that therapy with a calcium channel blocker and an inhibitor of the renin-angiotensin system is one effective strategy for lowering blood pressure and improving outcomes in these populations. (J Clin Hypertens (Greenwich). 2008;10(1 suppl 1):40-48) ${ }^{\circ} 2008$ Le Jacq

From the University of Michigan Health Care System, Ann Arbor, MI; ${ }^{1}$ the Primary Care Service Line, Ralph H. Johnson VA Medical Center, Charleston, SC; ${ }^{2}$ and the Division of General Internal Medicine/Geriatrics, Medical University of South Carolina, Charleston, $S^{3}$ Address for correspondence:

Kenneth A. Jamerson, MD, Division of Cardiovascular Medicine, Department of Internal Medicine, University of Michigan Health System, Ann Arbor, MI 48109 E-mail: jamerson@umich.edu
$\mathrm{T}^{\mathrm{h}}$ The importance of hypertension as a continuous, consistent, and independent risk factor for cardiovascular disease (CVD) is well established. ${ }^{1}$ Accordingly, recent treatment guidelines have particularly focused on specific subgroups of patients in whom uncontrolled or poorly controlled blood pressure (BP) confers a disproportionately high level of cardiovascular risk..$^{2,3}$ These groups include the elderly, patients with stage 2 hypertension (systolic BP $\geq 160 \mathrm{~mm} \mathrm{Hg}$ or diastolic $\mathrm{BP} \geq 100 \mathrm{~mm} \mathrm{Hg}$ ), black patients, and hypertensive patients with diabetes mellitus. Hypertension in these populations often poses treatment challenges. In the elderly, for example, age-related changes lead to alterations in the nature of hypertension, as vascular compliance decreases, pulse pressure widens, and isolated systolic BP becomes more prevalent. ${ }^{4}$ Although systolic BP plays a predominant role as a predictor of cardiac events in elderly patients, it is also more difficult to control than diastolic BP. (See the article in this supplement on BP control in the elderly by Drs Neutel and Gilderman.)

This article discusses hypertension in 3 other populations that, like the elderly, are considered at high risk, namely, patients with stage 2 hypertension, black patients, and patients with diabetes. These 3 groups are among those identified in the Seventh Report of the Joint National Committee on Prevention, Detection, Evaluation, and Treatment of High Blood Pressure (JNC 7) ${ }^{1}$ as requiring special consideration. Treatment guidelines emphasize the importance of reaching target BP goals $(<140 / 90 \mathrm{~mm} \mathrm{Hg}$, or $<130 / 80$ $\mathrm{mm} \mathrm{Hg}$ in patients with diabetes mellitus or other conditions that confer high risk), with the ultimate aim of reducing cardiovascular morbidity and mortality. ${ }^{1,5-8}$ In addition to goal attainment itself, the time to $\mathrm{BP}$ control should be 
considered. The achievement of prompt BP control has emerged as a goal of treatment based on findings from the Valsartan Antihypertensive LongTerm Use Evaluation (VALUE) ${ }^{9,10}$ as well as some other trials. The need for early and adequate drug therapy to rapidly get patients' BP to goal has once again been emphasized by a recent report by an international working group. ${ }^{11}$ Meeting BP goals for high-risk patients in a timely fashion will generally require the use of multiple-drug therapy.

\section{CHALLENGES FOR ACHIEVING PROMPT BP CONTROL IN HIGH-RISK PATIENTS}

\section{Stage 2 Hypertension}

A meta-analysis of data from 1 million adults in 61 prospective studies found that the higher the BP, the greater the risk. Death due to ischemic heart disease, stroke, and other vascular causes doubled with every $20-\mathrm{mm} \mathrm{Hg}$ systolic BP and $10-\mathrm{mm}$ $\mathrm{Hg}$ diastolic BP increase above $115 / 75 \mathrm{~mm} \mathrm{Hg} .{ }^{12}$ Evidence from clinical trials indicates that antihypertensive treatment is associated with reductions of $35 \%$ to $40 \%$ in the risk of stroke, $20 \%$ to $25 \%$ in myocardial infarction, and $>50 \%$ in heart failure, with larger BP reductions producing greater reductions in risk. ${ }^{13-15}$ Even small changes in BP result in large changes in risk, however, as each $2-\mathrm{mm} \mathrm{Hg}$ reduction in systolic BP results in approximately a $10 \%$ reduction in cardiovascular events.

\section{Black Patients}

Hypertension affects $>40 \%$ of the adult population, and black persons tend to experience more severe hypertension at an earlier age. ${ }^{16}$ As a result, they have an increased risk of virtually every complication of hypertension. ${ }^{17-19}$ Black persons have a 1.3 times greater rate of nonfatal stroke, 1.8 times greater rate of fatal stroke, 1.5 times greater rate of heart disease death, 4.2 times greater rate of end-stage kidney disease, and a $50 \%$ higher frequency of heart failure than the general population. ${ }^{19}$ Because black persons tend to experience an earlier onset and greater severity of hypertension as well as more target organ damage, the International Society on Hypertension in Blacks (ISHIB) Working Group has recommended that early identification of high-normal BP (130-139/85-89 $\mathrm{mm} \mathrm{Hg}$ ) and aggressive treatment are especially important in these patients. ${ }^{6}$

Control of BP in black persons poses distinct clinical challenges. Some studies have raised the possibility that differences based on race/ethnicity ${ }^{18}$ may influence response to antihypertensive therapy, whereas other investigators have concluded that the variability observed in patient response to $\mathrm{BP}$ medications originates within, not between, racial/ ethnic groups. ${ }^{20}$ The use of $\beta$-blockers and agents that act on the renin-angiotensin system (RAS) has at times been avoided in black patients because some evidence has indicated that they are less effective as monotherapy than are volume-responsive agents such as diuretics and calcium channel blockers (CCBs). ${ }^{1}$ Some but not all studies have suggested that these differences may be overcome by the use of higher doses of RAS-inhibiting agents or by the combination of an RAS-inhibiting agent with a diuretic or other drug. ${ }^{21}$ Cardiovascular risk and not ethnicity should be used to develop an appropriate antihypertensive regimen for patients with hypertension. Race alone should not be used as a reason to withhold RAS blockade when indicated for treatment of proteinuria and hypertension associated with diabetes or chronic kidney disease. While black patients have a higher relative risk of angioedema from angiotensin-converting enzyme (ACE) inhibitors compared with other patients, ${ }^{22}$ the use of ACE inhibitor and angiotensin II receptor blocker $(\mathrm{ARB})$ therapy along with diuretic or CCB treatment will allow for more effective BP control in a greater number of patients, regardless of skin color.

\section{Hypertension and Diabetes Mellitus}

Hypertension and diabetes frequently coexist, as hypertension is both a risk factor for and a consequence of diabetes. ${ }^{3,23}$ A large prospective study reported that diabetes was nearly 2.5 times as likely to develop in persons with high BP as in their normotensive counterparts, regardless of specific treatment. ${ }^{24}$ Other studies show an increased prevalence of hypertension in persons with diabetes. ${ }^{25}$ Prevalence estimates vary depending on the defining criteria. For example, a retrospective chart analysis of diabetic patients found that the percentage of patients with concomitant hypertension was $60.2 \%, 76.5 \%$, and $85.8 \%$ at $\mathrm{BP}$ thresholds of $140 / 90,130 / 85$, and $130 / 80 \mathrm{~mm} \mathrm{Hg}$, respectively. ${ }^{26}$ CVD accounts for up to $80 \%$ of deaths in persons with diabetes. When hypertension is combined with diabetes, the risk is compounded even further. ${ }^{25}$

A body of evidence from clinical trials has shown that rigorous control of BP is particularly important in patients with hypertension and diabetes. For example, the Hypertension Optimal Treatment (HOT) trial ${ }^{27}$ found that lowering diastolic BP to a target level of $<80 \mathrm{~mm} \mathrm{Hg}$ (actual achieved BP level, $81 \mathrm{~mm} \mathrm{Hg}$ ) compared with a 
target of $<90 \mathrm{~mm} \mathrm{Hg}$ (actual achieved BP level, $85 \mathrm{~mm} \mathrm{Hg}$ ) in patients with diabetes reduced the risk of CVD events by $51 \%$. This study led to the establishment of lower diastolic BP goals $(<80 \mathrm{~mm}$ $\mathrm{Hg}$ ) in diabetic patients. In the United Kingdom Prospective Diabetes Study (UKPDS) 38, ${ }^{28}$ diabetic patients in the stricter BP control group (primarily using captopril-based or atenolol-based therapy), in whom a mean BP level of $144 / 82 \mathrm{~mm} \mathrm{Hg}$ was achieved, had a $34 \%(P=.019)$ reduction in risk of developing any macrovascular complication (sudden death, myocardial infarction, stroke, or peripheral vascular disease) compared with patients in the less strict control group, who had a mean BP level of $154 / 87 \mathrm{~mm} \mathrm{Hg}$. There was no difference in outcome between the $\beta$-blocker-based and the ACE inhibitor-based treatment groups. The BP difference accounted for the benefit in outcome.

In the subset of diabetic patients in the Losartan Intervention for Endpoint Reduction in Hypertension (LIFE) study, ${ }^{29}$ the difference in achieved BP with losartan-based therapy vs atenolol-based therapy was small $(146 / 79 \mathrm{~mm} \mathrm{Hg}$ vs $148 / 79 \mathrm{~mm} \mathrm{Hg}$, respectively), but losartan use was associated with a $24 \%$ relative reduction in risk of CVD ( $P=.031$; primarily stroke) compared with atenolol. Once again, seemingly small changes in BP translated into differences in clinical outcome. The LIFE study investigators suggested that in patients with diabetes, the use of an ARB-based regimen might have benefits beyond BP reduction. $^{29}$ The first priority, however, in all patients with hypertension, including those with diabetes, is to reduce BP to goal.

Major treatment guidelines recommend a BP target of $130 / 80 \mathrm{~mm} \mathrm{Hg}$ in patients with diabetes. ${ }^{1,5,7}$ The ongoing Stop Atherosclerosis in Native Diabetics Study (SANDS) ${ }^{30}$ and the Action to Control Cardiovascular Risk in Diabetes (ACCORD) trial ${ }^{31}$ will provide further information on the most appropriate target BP in diabetic patients. The BP arm of the ACCORD trial, for example, will examine the effects on cardiovascular events of lowering systolic BP to a goal of $<120$ $\mathrm{mm} \mathrm{Hg}$, compared with $<140 \mathrm{~mm} \mathrm{Hg}$, within the context of good glycemic control.

\section{RATIONALE FOR COMBINATION THERAPY}

Data from the National Health and Nutrition Examination Survey (NHANES) indicate that BP control rates in the United States remain low, especially in high-risk groups. ${ }^{16,32-34}$ For example, the BP control rate in the United States in 2003 to 2004 was only $52.4 \%$ among treated non-Hispanic black patients and $37.5 \%$ among all treated diabetic patients. ${ }^{32}$ Even with appropriate use of lifestyle modifications, most patients with hypertension will require pharmacologic treatment to control BP. In fact, clinical trial results indicate that in most persons with hypertension, $\geq 2$ antihypertensive agents are required to achieve BP targets, and all major treatment guidelines support the use of $\geq 2$ antihypertensive agents in patients at high risk. ${ }^{1,5,6}$

Patients with more severe hypertension, including black persons, usually require $\geq 2$ drugs for BP targets to be reached in a timely manner. According to JNC 7, initial therapy with 2 drugs, separately or as fixed-dose combinations, should be considered when systolic BP is $>20 \mathrm{~mm} \mathrm{Hg}$ or diastolic BP is $>10 \mathrm{~mm} \mathrm{Hg}$ above the desired goal for the patient. ${ }^{1}$ The 2007 European Society of Hypertension/ European Society of Cardiology practice guidelines state that 2 drugs, separately or in combination, are preferred as first-step treatment in grade 2 $(160-179 / 100-109 \mathrm{~mm} \mathrm{Hg})$ or grade 3 ( $\geq 180 / \geq 110$ $\mathrm{mm} \mathrm{Hg}$ ) hypertension or when total cardiovascular risk is high or very high. ${ }^{5} \mathrm{~A}$ diuretic is often included as one component of combination therapy, since this strategy elicits a greater response than singleagent therapy alone. ${ }^{35}$ Whether this strategy is better than using a CCB as one of the components remains unclear. Fixed-dose combinations of a diuretic or CCB plus a wide variety of antihypertensive classes are available and constitute a useful option for patients with stage 2 hypertension. For example, a number of studies have demonstrated the efficacy and tolerability of treatment with a diuretic or CCB plus either an ACE inhibitor or an ARB in stage 2 hypertension. ${ }^{36-42}$

The ISHIB recommends initiating 2-drug therapy in black patients when BP is $\geq 15 / 10 \mathrm{~mm} \mathrm{Hg}$ above goal. ${ }^{6}$ As mentioned, monotherapy with RAS blockers is usually considered less effective in black patients. Differences in response, however, may be overcome by the administration of additional antihypertensive therapy, especially a diuretic. ${ }^{1}$ As in patients with stage 2 hypertension, the role of diuretic-based combination therapy in black patients is well established and supported by the guidelines. ${ }^{6}$ More recently, the use of alternative combinations, such as an RAS blocker with a CCB, has been explored. ${ }^{36,37,41}$

Aggressive BP targets may be particularly difficult to achieve in patients with diabetes mellitus. 1,7,28,43 Although intense nonpharmacologic measures, particularly weight loss and reduction of salt intake, should be encouraged in all hypertensive diabetic patients, ${ }^{5}$ combination drug therapy 
with $\geq 2$ agents is generally required to achieve appropriate BP targets. ${ }^{1,5,7}$

\section{CLINICAL TRIALS OF CCBs PLUS RAS INHIBITORS IN HIGH-RISK POPULATIONS}

By targeting different key mechanisms involved in BP regulation, the combination of a CCB with an RAS blocker offers another possible alternative for prompt and additive BP reductions without an increase in adverse events. ${ }^{44}$ Combinations of a CCB with an ACE inhibitor have been available for a number of years, and one such combination is being compared with combined ACE inhibitor/diuretic therapy in the ongoing Avoiding Cardiovascular Events Through Combination Therapy in Patients Living With Systolic Hypertension (ACCOMPLISH) trial. ${ }^{45}$ The following section will primarily focus on the newest combination agents, a CCB with an ARB.

\section{Stage 2 Hypertension}

Clinical trials in patients with stage 2 hypertension have consistently shown the benefit of combining a CCB with an ACE inhibitor. ${ }^{35,46,47}$ Recent trials have also established the efficacy and tolerability of combining an ARB with a CCB in high-risk populations, including patients with stage 2 hypertension. ${ }^{41,42,48}$

A study reporting the results of 2 randomized, double-blind, placebo-controlled, parallel-group 8 -week trials in patients with mild to moderate hypertension (mean sitting diastolic BP level $>95 \mathrm{~mm} \mathrm{Hg}$ and $<110 \mathrm{mg} \mathrm{Hg}$ ) demonstrated (as expected) greater BP reductions overall with amlodipine/valsartan combination therapy compared with the monotherapy components. ${ }^{42} \mathrm{~A}$ post hoc subgroup analysis of patients with stage 2 hypertension showed that this combination was associated with greater BP-lowering effects in this population compared with each respective monotherapy and placebo (Figure 1). ${ }^{48}$ Patients with stage 2 hypertension generally had greater reductions in mean sitting $\mathrm{BP}$ than did patients with stage 1 hypertension. ${ }^{48}$ For example, reductions with amlodipine $10 \mathrm{mg}$ plus valsartan 160 $\mathrm{mg}$ were $29.6 / 17.6 \mathrm{~mm} \mathrm{Hg}$ in patients with stage 2 hypertension compared with 20.3/16.5 $\mathrm{mm} \mathrm{Hg}$ in patients with stage 1 hypertension; the reductions with amlodipine $10 \mathrm{mg}$ plus a large dose of valsar$\tan (320 \mathrm{mg})$ were $29.6 / 18.1$ and $22.7 / 18.2 \mathrm{~mm}$ $\mathrm{Hg}$, respectively. The incidence of adverse events in patients with stage 2 hypertension with combination therapy $(42.5 \%)$ was generally comparable to that with monotherapy (valsartan, $37.4 \%$; amlodipine, $43.0 \%$; placebo, $36.5 \%) .{ }^{48}$

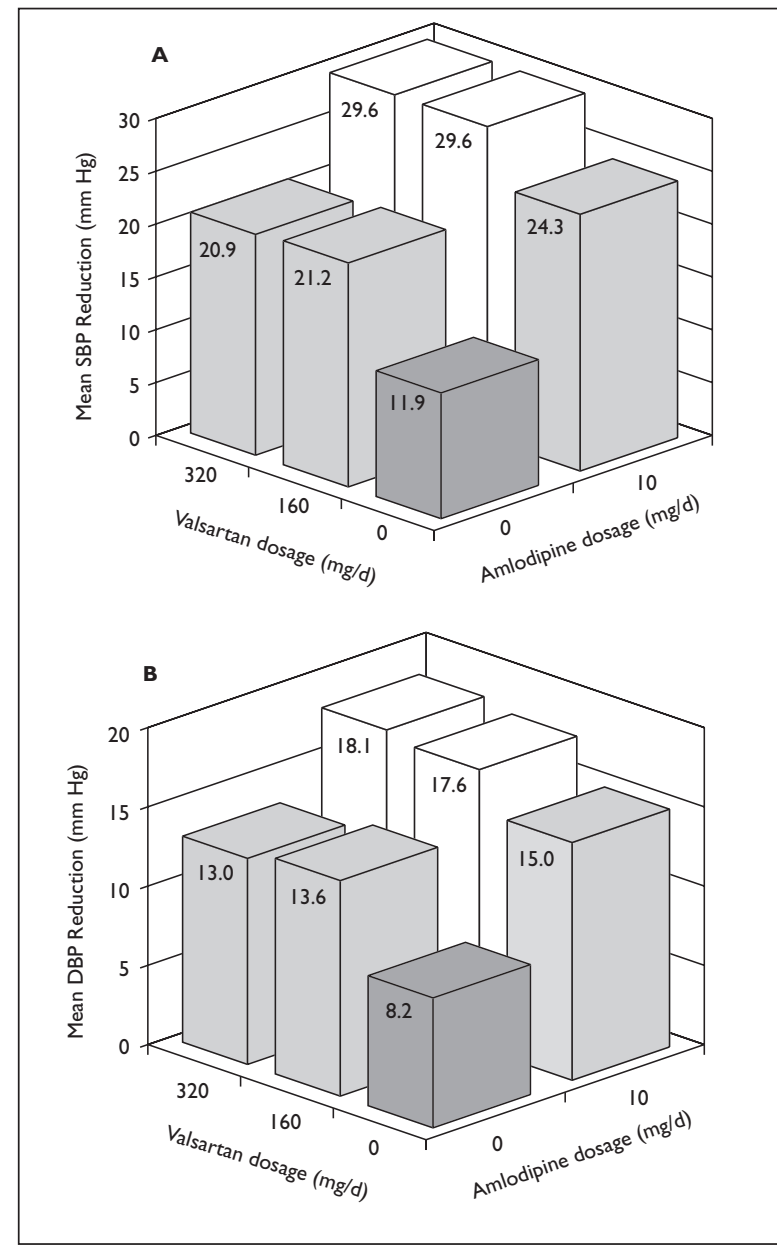

Figure 1. Change from baseline in mean sitting systolic blood pressure (SBP) (A) and mean sitting diastolic blood pressure $(D B P)(B)$ in patients with stage 2 bypertension (baseline systolic blood pressure $\geq 160 \mathrm{~mm}$ $\mathrm{Hg}$ and/or baseline diastolic blood pressure $\geq 100 \mathrm{~mm}$ $\mathrm{Hg}$ ). Patients received amlodipine $10 \mathrm{mg}$, valsartan 160 or $320 \mathrm{mg}$, combination therapy with amlodipine and valsartan at these same doses, or placebo. Reprinted with permission from Smith et al. ${ }^{48}$

In another study, therapy with amlodipine plus valsartan was as effective and well tolerated as lisinopril plus hydrochlorothiazide in patients with stage 2 hypertension (mean sitting diastolic $\mathrm{BP} \geq 110 \mathrm{~mm} \mathrm{Hg}$ and $<120 \mathrm{~mm} \mathrm{Hg})^{41}$ Both treatments were associated with the achievement of BP goals $(<140 / 90 \mathrm{~mm} \mathrm{Hg})$ in the majority of patients $(67.2 \%$ for the amlodipine/valsartan group and $56.1 \%$ for the lisinopril/hydrochlorothiazide group). ${ }^{41}$ Finally, a trial in 1940 patients with seated diastolic BP levels $\geq 95$ and $\leq 120 \mathrm{~mm}$ $\mathrm{Hg}$ reported (again as expected) greater reductions in mean seated systolic BP and diastolic BP values with combinations of amlodipine 5 to $10 \mathrm{mg} / \mathrm{d}$ plus olmesartan 10 to $40 \mathrm{mg} / \mathrm{d}$ for 8 weeks, compared with the respective monotherapy components. ${ }^{49}$ 


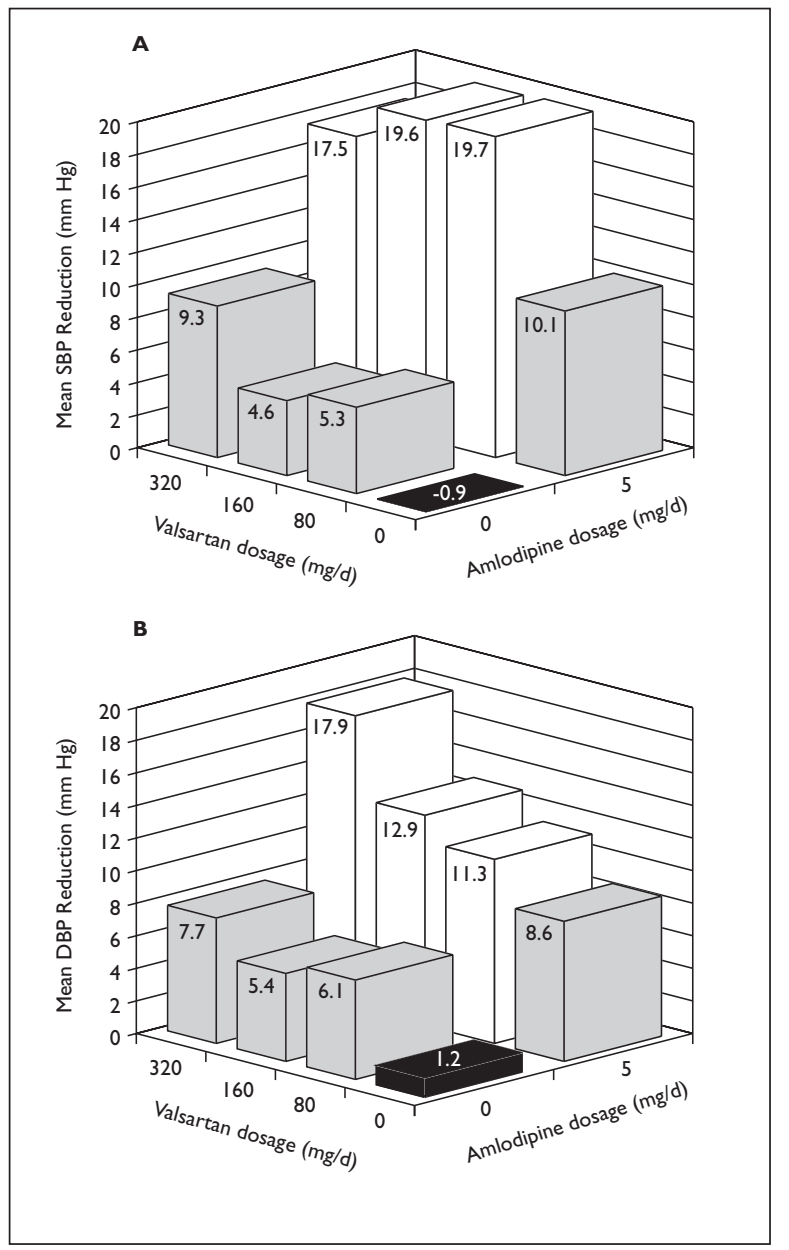

Figure 2. Change from baseline in mean sitting systolic blood pressure (SBP) (A) and mean sitting diastolic blood pressure $(D B P)(B)$ in black patients treated who received amlodipine $5 \mathrm{mg}$, valsartan 160 or $320 \mathrm{mg}$, combination therapy with amlodipine $5 \mathrm{mg}$ plus valsartan 160 or 320 $\mathrm{mg}$, or placebo. Adapted from Smith et al. ${ }^{48}$

The greatest reductions in mean seated systolic/ diastolic BP occurred with amlodipine $10 \mathrm{mg}$ plus olmesartan $40 \mathrm{mg}(-30.1 /-19.0 \mathrm{~mm} \mathrm{Hg}$ vs $-4.8 /-3.1 \mathrm{~mm} \mathrm{Hg}$ with placebo and $-19.7 /-12.7$ $\mathrm{mm} \mathrm{Hg}$ with amlodipine $10 \mathrm{mg}) .{ }^{49}$

\section{Black Patients}

There is good rationale for including an RASblocking agent as one element of combination therapy in black persons who have an increased risk of CVD and are almost twice as likely to develop diabetes as age-matched non-Hispanic whites. ${ }^{50}$ Inhibition of the RAS also has renoprotective effects in black patients with hypertensive nephrosclerosis. ${ }^{51}$ The combination of an ACE inhibitor or an ARB with a diuretic is established therapy in this population. ${ }^{6}$ Evidence is beginning to emerge regarding the potential usefulness of RAS blockers combined with CCBs. A prespecified subgroup analysis by Smith and colleagues $^{48}$ showed that amlodipine/valsartan combination therapy was associated with substantial BP-lowering effects in black patients (Figure 2); however, the number of patients in this subset was small. Future trials will need to include more black participants to determine the best combinations of antihypertensive agents in this population.

\section{Diabetes}

Major treatment guidelines for patients with concomitant hypertension and diabetes recommend the use of ACE inhibitors or ARBs as one component of therapy because these agents may prevent or delay albuminuria and adverse metabolic outcomes in addition to lowering BP. , $^{1,7} \mathrm{~A}$ number of recent trials and meta-analyses have also demonstrated that fewer cases of new-onset diabetes occur when $\mathrm{ARBs}$ or ACE inhibitors are used, compared with other agents. ${ }^{9,52-58}$ In addition, ACE inhibitors and ARBs have been shown to improve insulin sensitivity ${ }^{59,60}$ and to reduce the risk of the development or progression of diabetic nephropathy. ${ }^{61,62}$ The guidelines do not provide suggestions as to whether to initiate therapy with an ACE inhibitor or an ARB; however, if either class of RAS-blocking drug is not tolerated (eg, ACE inhibitor-induced cough), an agent from the other class should be used., ${ }^{7,63} \mathrm{At}$ least 2 drugs will typically be required to achieve the stringent BP goal of $<130 / 80 \mathrm{~mm} \mathrm{Hg}$ in most diabetic patients. ${ }^{1,7}$ An RAS blocker should always be one component of combination therapy in hypertensive patients with diabetes. The other agent might be a diuretic, but CCBs, which do not have adverse effects on the metabolic profile, may also be considered.

The Action in Diabetes and Vascular Disease: Preterax and Diamicron-MR Controlled Evaluation (ADVANCE) trial ${ }^{64}$ randomized $>11,000$ diabetic patients with a history of CVD or one other risk factor for CVD to either a fixed-dose combination of perindopril and indapamide or placebo. Patients could be enrolled whether they were hypertensive or normotensive. With the exception of another ACE inhibitor, all other drugs already being taken at enrollment were continued, and other drugs, except for thiazide diuretics or an ACE inhibitor other than perindopril, could be added during the trial. The mean entry BP value of randomized patients was $145 / 81 \mathrm{~mm} \mathrm{Hg}$, and $41 \%$ had BP < $140 / 90 \mathrm{~mm} \mathrm{Hg}$. During a mean follow-up of 4.3 years, participants receiving combination therapy with perindopril 2 


\begin{tabular}{|c|c|c|c|}
\hline & \multicolumn{2}{|c|}{$\begin{array}{c}\text { Number }(\%) \text { of patients } \\
\text { with event }\end{array}$} & \multirow[b]{2}{*}{$\begin{array}{c}\text { Relative risk } \\
\text { reduction } \\
(95 \% \mathrm{Cl})\end{array}$} \\
\hline & $\begin{array}{c}\text { Perindopril- } \\
\text { indapamide } \\
(\mathrm{N}=5569)\end{array}$ & $\begin{array}{l}\text { Placebo } \\
(N=5571)\end{array}$ & \\
\hline Combined macro+micro & 861 (I5.5\%) & $938(16.8 \%)$ & $9 \%(0$ to 17$)$ \\
\hline Macrovascular & 480 (8.6\%) & $520(9.3 \%)$ & $8 \%(-4$ to 19$)$ \\
\hline Microvascular & 439 (7.9\%) & $477(8.6 \%)$ & $9 \%(-4$ to 20$)$ \\
\hline All deaths & $408(7.3 \%)$ & $471(8.5 \%)$ & $14 \%$ (2 to 25$)$ \\
\hline \multirow[t]{4}{*}{ Cardiovascular death } & $211(3.8 \%)$ & $257(4.6 \%)$ & $18 \%(2$ to 32$)$ \\
\hline & & 0.5 & 2.0 \\
\hline & & \multicolumn{2}{|c|}{ Hazard ratio } \\
\hline & & $\begin{array}{c}\text { Favors } \\
\text { perindopril- } \\
\text { indapamide }\end{array}$ & $\begin{array}{l}\text { Favors } \\
\text { placebo }\end{array}$ \\
\hline
\end{tabular}

Figure 3. Effects of combination treatment with perindopril plus indapamide vs placebo on deaths and macrovascular and microvascular events in patients with diabetes mellitus in the Action in Diabetes and Vascular Disease: Preterax and Diamicron-MR Controlled Evaluation (ADVANCE) trial. Black squares indicate point estimates; horizontal lines, 95\% confidence intervals (CIs); diamonds, point estimate and 95\% CIs for overall effects; vertical broken lines, point estimates for overall effect within categories. Adapted with permission from ADVANCE Collaborative Group. ${ }^{64}$

to $4 \mathrm{mg}$ /indapamide 0.625 to $1.25 \mathrm{mg}$ plus other medications had mean reductions of $5.6 / 2.2 \mathrm{~mm}$ $\mathrm{Hg}$, compared with those taking medications other than the specific study drugs, and a $9 \%$ reduction in relative risk of major macrovascular or microvascular events $(P=.04)$ (Figure 3). The overall risk of death was reduced by $14 \%$ in the active-treatment group $\left(P=.025\right.$ vs placebo) ${ }^{64}$

Support for the utility of fixed-dose CCB/ RAS-blocking combination products in achieving prompt BP control is also emerging from preliminary results of the ACCOMPLISH trial. ${ }^{65}$ This study has enrolled 11,463 patients with a mean age of 68 years who have a history of coronary disease $(46 \%)$, stroke $(13 \%)$, or diabetes $(60 \%)$. The study objective is to test whether initial combination therapy with an ACE inhibitor and a CCB (benazepril/amlodipine) differs from initial combination therapy with an ACE inhibitor and a diuretic (benazepril/hydrochlorothiazide) on a composite of fatal and nonfatal cardiovascular events. ${ }^{66}$ A report of BP-lowering effects during the first 6 months of treatment indicates that the BP control rate was $73 \%$ in the overall trial population using initial combination therapy. ${ }^{65}$ There is also evidence of excellent systolic BP control at 18 months, with a BP level $<140 / 90 \mathrm{~mm} \mathrm{Hg}$ achieved in about $76 \%$ of the patient population, which is still blinded to treatment group. ${ }^{67}$ It is therefore possible that BP had been lowered in a high percentage of patients in both treatment groups.

End point data for the combination of a CCB plus an ARB in hypertensive diabetic patients are not yet available; however, some animal and preclinical studies suggest that this combination may be beneficial in this population. For example, an animal study showed that combined $\mathrm{CCB}$ and $\mathrm{ARB}$ therapy was more effective than either monotherapy in reducing glucose intolerance. ${ }^{68}$ In another study, the addition of valsartan to antihypertensive medications that included an ACE inhibitor or a CCB resulted in improvement in resistance artery remodeling in diabetic hypertensive patients, whereas the addition of atenolol did not. ${ }^{69}$

\section{CONCLUSIONS}

Patients with stage 2 hypertension, black patients with hypertension, and patients with both hypertension and diabetes exhibit a disproportionately high level of cardiovascular risk. In addition, these groups pose greater challenges in terms of treatment. BP control in these groups often remains suboptimal, contributing to the burden of CVD morbidity and mortality. Multiple-drug therapy, 
either as 2 drugs given separately or as a fixed-dose combination, may result in more prompt achievement of BP goals. Recent evidence indicates that combination therapy with a CCB and an inhibitor of the RAS provides prompt BP reductions and excellent tolerability in patients with stage 2 hypertension, hypertensive black patients, and patients with hypertension and diabetes. The answer to the question of whether and to what extent combined $\mathrm{CCB} / \mathrm{ARB}$ therapy also decreases the risk of clinical CVD events to the same or greater degree as other agents awaits the performance of future clinical trials.

Disclosures: Dr Basile receives grant/research support from the National Heart, Lung, and Blood Institute; Boehringer Ingelheim (ONTARGET); and Novartis. He has served as a consultant for AstraZeneca, Merck, Novartis, and Daiichi Sankyo and has served on the Speakers' Bureau of Abbott, AstraZeneca, Boehringer Ingelheim, Forest, Merck, Novartis, Pfizer, and Daiichi Sankyo. Dr Jamerson has received grants/research support from King Pharmaceuticals; the National Heart, Lung, and Blood Institute; the National Institute of Diabetes and Digestive and Kidney Diseases; Novartis, and Speedel. He has served as a consultant for Merck, Novartis, Pfizer, SanofiAventis, Sankyo, and Speedel and on the Speakers' Bureau for Abbott, GlaxoSmithKline, Merck, Nitromed, and Novartis. The authors acknowledge the assistance of Landmark Programs, Inc. in preparing this review article and styling the paper for journal submission. Editorial support was funded by Novartis Pharmaceuticals Corporation and the authors received an honorarium for time and effort spent preparing this article.

\section{REFERENCES}

1 Seventh Report of the Joint National Committee on Prevention, Detection, Evaluation, and Treatment of High Blood Pressure. Hypertension. 2003;42:1206-1252.

2 Levine RS, Foster JE, Fullilove RE, et al. Black-white inequalities in mortality and life expectancy, 1933-1999: implications for Healthy People 2010. Pub Health Rep. 2001;116:474-483.

3 Schutta MH. Diabetes and hypertension: epidemiology of the relationship and pathophysiology of factors associated with these comorbid conditions. J Cardiometab Syndr. 2007;2:124-130.

4 Franklin SS, Khan SA, Wong ND, et al. Is pulse pressure useful in predicting risk for coronary heart disease? The Framingham Heart Study. Circulation. 1999;100:354-360.

5 The Task Force for the Management of Arterial Hypertension of the European Society of Hypertension (ESH) and of the European Society of Cardiology (ESC). 2007 Guidelines for the management of arterial hypertension. Eur Heart J. 2007;28:1462-1536.

6 Douglas JG, Bakris GL, Epstein M, et al; Hypertension in African Americans Working Group. Management of high blood pressure in African Americans: consensus statement of the Hypertension in African Americans Working Group of the International Society on Hypertension in Blacks. Arch Intern Med. 2003;163:525-541.

7 American Diabetes Association. Hypertension management in adults with diabetes. Diabetes Care. 2004;27(suppl 1):S65-S67.

8 Bakris GL, Williams M, Dworkin L, et al; National Kidney Foundation Hypertension and Diabetes Executive Committees Working Group. Preserving renal function in adults with hypertension and diabetes: a consensus approach. Am J Kidney Dis. 2000;36:646-661.

9 Julius S, Kjeldsen SE, Weber $M$, et al; VALUE trial group. Outcomes in hypertensive patients at high cardiovascular risk treated with regimens based on valsartan or amlodipine: the VALUE randomised trial. Lancet. 2004;363:2022-2031.

10 Weber MA, Julius S, Kjeldsen SE, et al. Blood pressure dependent and independent effects of antihypertensive treatment on clinical events in the VALUE Trial. Lancet. 2004;363:2049-2051.

11 Bakris G, Hill M, Mancia G, et al. Achieving blood pressure goals globally: five core actions for health-care professions. A worldwide call to action. J Hum Hypertens. 2007 Aug 30; [Epub ahead of print].

12 Prospective Studies Collaboration. Age-specific relevance of usual blood pressure to vascular mortality: a meta-analysis of individual data for one million adults in 61 prospective studies. Lancet. 2002;360:1903-1913.

13 Staessen JA, Wang J-G, Thijs L. Cardiovascular prevention and blood pressure reduction: a quantitative overview updated until 1 March 2003. J Hypertens. 2003;21:1055-1076.

14 Blood Pressure Lowering Treatment Trialists' Collaboration. Effects of ACE inhibitors, calcium antagonists, and other blood pressure-lowering drugs: results of prospectively designed overviews of randomised trials. Lancet. 2000;355:1955-1964.

15 Blood Pressure Lowering Treatment Trialists' Collaboration. Effects of different blood-pressure-lowering regimens on major cardiovascular events: results of prospectively-designed overviews of randomised trials. Lancet. 2003;362:1527-1535.

16 American Heart Association. Heart Disease and Stroke Statistics-2007 Update. Dallas, TX: American Heart Association; 2007.

17 Ferdinand KC, Saunders E. Hypertension-related morbidity and mortality in African Americans-why we need to do better. J Clin Hypertens (Greenwich). 2006;8(1 suppl 1):21-30.

18 Berenson G, Srinivasan S, Chen W, et al; Bogalusa Heart Study Group. Racial (black-white) contrasts of risk for hypertensive disease in youth have implications for preventive care: the Bogalusa Heart Study. Ethn Dis. 2006;16(3 suppl 4):S4-2-S4-9.

19 Ferdinand KC, Armani AM. The management of hypertension in African Americans. Crit Pathw Cardiol. 2007;6:67-71.

20 Mokwe E, Ohmit SE, Nasser SA, et al. Determinants of blood pressure response to quinapril in black and white hypertensive patients: the Quinapril Titration Interval Managment Evaluation trial. Hypertension. 2004;43:1202-1207.

21 Flack JM, Mensah GA, Ferrario CM. Using angiotensin converting enzyme inhibitors in African-American hypertensives: a new approach to treating hypertension and preventing target-organ damage. Curr Med Res Opin. 2000;16:66-79.

22 McDowell SE, Coleman JJ, Ferner RE. Systematic review and meta-analysis of ethnic differences in risks of adverse reactions to drugs used in cardiovascular medicine. BMJ. 2006;332:1177-1181.

23 Weycker D, Nichols GA, O'Keeffe-Rosetti M, et al. Riskfactor clustering and cardiovascular disease risk in hypertensive patients. Am J Hypertens. 2007;20:599-607.

24 Gress TW, Nieto FJ, Shahar E, et al; Atherosclerosis Risk in Communities Study. Hypertension and antihypertensive therapy as risk factors for type 2 diabetes mellitus. N Engl J Med. 2000;342:905-912.

25 Sowers JR, Epstein M, Frohlich ED. Diabetes, hypertension, and cardiovascular disease: an update. Hypertension. 2001;37:1053-1059.

26 Kabakov E, Norymberg C, Osher E, et al. Prevalence of hypertension in type 2 diabetes mellitus: impact of the tightening definition of high blood pressure and association 
with confounding risk factors. J Cardiometab Syndr. 2006;1:95-101.

27 Hansson L, Zanchetti A, Carruthers SG, et al; HOT Study Group. Effects of intensive blood-pressure lowering and low-dose aspirin in patients with hypertension: principal results of the Hypertension Optimal Treatment (HOT) randomised trial. Lancet. 1998;351:1755-1762.

28 UK Prospective Diabetes Study Group. Tight blood pressure control and risk of macrovascular and microvascular complications in type 2 diabetes: UKPDS 38. BMJ. 1998;317:703-713.

29 Lindholm LH, Ibsen H, Dahlöf B, et al; LIFE Study Group. Cardiovascular morbidity and mortality in patients with diabetes in the Losartan Intervention For Endpoint reduction in hypertension study (LIFE): a randomised trial against atenolol. Lancet. 2002;359(9311):1004-1010.

30 Russell M, Fleg JL, Galloway J, et al. Examination of lower targets for low-density lipoprotein cholesterol and blood pressure in diabetes-the Stop Atherosclerosis in Native Diabetics Study (SANDS). Am Heart J. 2006;152:867-875.

31 Cushman WC, Grimm RH Jr, Cutler JA, et al; ACCORD Study Group. Rationale and design for the blood pressure intervention of the Action to Control Cardiovascular Risk in Diabetes (ACCORD) trial. Am J Cardiol. 2007; 99 (12A):44i-55i

32 Ong KL, Cheung BMY, Man YB, et al. Prevalence, awareness, treatment, and control of hypertension among United States adults 1999-2004. Hypertension. 2007;49:69-75.

33 Giles T, Aranda JM Jr, Suh DC, et al. Ethnic/racial variations in blood pressure awareness, treatment, and control. J Clin Hypertens (Greenwich). 2007;9:345-354.

34 Hertz RP, Unger AN, Cornell JA, et al. Racial disparities in hypertension prevalence, awareness, and management. Arch Intern Med. 2005;165:2098-2104.

35 Neutel JM, Black HR, Weber MA. Combination therapy with diuretics: an evolution of understanding. Am J Med. 1996;101:61S-70S.

36 Bakris GL, Weir MR; Study of Hypertension and the Efficacy of Lotrel in Diabetes (SHIELD) Investigators. Achieving goal blood pressure in patients with type 2 diabetes: conventional versus fixed-dose combination approaches. J Clin Hypertens (Greenwich). 2003;5:202-209.

37 Jamerson KA, Nwose O, Jean-Louis L, et al. Initial angiotensin-converting enzyme inhibitor/calcium channel blocker combination therapy achieves superior blood pressure control compared with calcium channel blocker monotherapy in patients with stage 2 hypertension. Am J Hypertens. 2004;17:495-501.

38 Neutel JM, Smith DH, Weber MA, et al. Efficacy of combination therapy for systolic blood pressure in patients with severe systolic hypertension: the Systolic Evaluation of Lotrel Efficacy and Comparative Therapies (SELECT) study. I Clin Hypertens (Greenwich). 2005;7:641-646.

39 Ruilope LM, Malacco E, Khder Y, et al. Efficacy and tolerability of combination therapy with valsartan plus hydrochlorothiazide compared with amlodipine monotherapy in hypertensive patients with other cardiovascular risk factors: the VAST study. Clin Ther. 2005;27:578-588.

40 Neutel JM, Franklin SS, Oparil S, et al. Efficacy and safety of irbesartan/HCTZ combination therapy as initial treatment for rapid control of severe hypertension. J Clin Hypertens (Greenwich). 2006;8:850-857.

41 Poldermans D, Glazer R, Karagiannis S, et al. Tolerability and blood pressure-lowering efficacy of the combination of amlodipine plus valsartan compared with lisinopril plus hydrocholorothiazide in adult patients with stage 2 hypertension. Clin Ther. 2007;29:279-289.

42 Philipp T, Smith TR, Glazer R, et al. Two multicenter, 8-week, randomized, double-blind, placebo-controlled, parallel-group studies evaluating the efficacy and tolerability of amlodipine and valsartan in combination and as monotherapy in adult patients with mild to moderate essential hypertension. Clin Ther. 2007;29:563-580.

43 Estacio RO, Jeffers BW, Hiatt WR, et al. The effect of nisoldipine as compared with enalapril on cardiovascular outcomes in patients with non-insulin-dependent diabetes and hypertension. N Engl J Med. 1998;338:645-652.

44 Kjeldsen SE, Aksnes TA, de la Sierra A, et al. Amlodipine and valsartan: calcium channel blockers/angiotensin II receptor blockers combination for hypertension. Therapy. 2007;4:31-40.

45 Jamerson KA, Bakris GL, Wun CC, et al. Rationale and design of the Avoiding Cardiovascular Events Through Combination Therapy in Patients Living With Systolic Hypertension (ACCOMPLISH) trial: the first randomized controlled trial to compare the clinical outcome effects of first-line combination therapies in hypertension. Am J Hypertens. 2004;17:793-801.

46 Dahlöf B, Sever PS, Poulter NR, et al; ASCOT investigators. Prevention of cardiovascular events with an antihypertensive regimen of amlodipine adding perindopril as required versus atenolol adding bendroflumethiazide as required, in the Anglo-Scandinavian Cardiac Outcomes Trial-Blood Pressure Lowering Arm (ASCOT-BPLA): a multicentre randomised controlled trial. Lancet. 2005;366:895-906.

47 Rubio-Guerra AF, Arceo-Navarro A, Lozano-Nuevo JJ, et al. Efficacy of a fixed-dose combination of trandolaprilverapamil in patients with stage 2 hypertension inadequately controlled by monotherapy. Clin Drug Invest. 2005;25:445-451.

48 Smith TR, Philipp T, Vaisse B, et al. Amlodipine and valsartan combined and as monotherapy in stage 2, elderly, and black hypertensive patients: subgroup analyses of two randomized, placebo-controlled studies. J Clin Hypertens (Greenwich). 2007;9:355-364.

49 Chrysant SG, Melino M, Karki S, et al. A randomized, double-blind, placebo-controlled factorial study evaluating the efficacy and safety of co-administration of amlodipine besylate (AML) plus olmesartan medoxomil (OM) compared to monotherapy in patients (PTS) with mild to severe hypertension (HTN) [abstract]. J Clin Hypertens (Greenwich). 2007;9:486.

50 National Diabetes Education Program. The Diabetes Epidemic Among African Americans Fact Sheet. Bethesda, MD: US Department of Health and Human Services, National Institute of Health; 2005.

51 Agodoa LY, Appel L, Bakris GL, et al; African American Study of Kidney Disease and Hypertension (AASK) Study Group. Effect of ramipril vs amlodipine on renal outcomes in hypertensive nephrosclerosis: a randomized controlled trial. JAMA. 2001;285:2719-2728.

52 Niklason A, Hedner T, Niskanen L, et al; CAPPP Study Group. Development of diabetes is retarded by ACE inhibition in hypertensive patients-a subanalysis of the Captopril Prevention Project (CAPPP). J Hypertens. 2004;22:645-652.

53 Lindholm LH, Ibsen $\mathrm{H}$, Borch-Johnsen $\mathrm{K}$, et al; LIFE Study Group. Risk of new-onset diabetes in the Losartan Intervention for Endpoint Reduction in Hypertension study. J Hypertens. 2002;20:1879-1886.

54 Andraws R, Brown DL. Effect of inhibition of the reninangiotensin system on development of type 2 diabetes mellitus (meta-analysis of randomized trials). Am J Cardiol. 2007;99:1006-1012.

55 Almgren T, Wilhelmsen L, Samuelsson O, et al. Diabetes in treated hypertension is common and carries a high cardiovascular risk: results from a 28-year follow-up. $J$ Hypertens. 2007;25:1311-1317.

56 Aksnes TA, Kjeldsen SE, Rostrup M, et al. Impact of newonset diabetes mellitus on cardiac outcomes in the valsartan antihypertensive long-term use evaluation (VALUE) trial population. Hypertension. 2007;50:467-473.

57 Kuti EL, Baker WL, White CM. The development of new-onset type 2 diabetes associated with choosing a calcium channel blocker compared to a diuretic or beta-blocker. 
Curr Med Res Opin. 2007;23:1239-1244.

58 Burke TA, Sturkenboom MC, Ohman-Strickland PA, et al. The effect of antihypertensive drugs and drug combinations on the incidence of new-onset type-2 diabetes mellitus. Pharmacoepidemiol Drug Saf. 2007;16:979-987.

59 Nawano M, Anai M, Funaki M, et al. Imadapril, an angiotensin-converting enzyme inhibitor, improves insulin sensitivity by enhancing signal transduction via insulin receptor substrate proteins and improving vascular resistance in the Zucker fatty rat. Metabolism. 1999;48:1248-1255.

60 Jin HM, Pan Y. Angiotensin type-1 receptor blockade with losartan increases insulin sensitivity and improves glucose homeostasis in subjects with type 2 diabetes and nephropathy. Nephrol Dial Transplant. 2007;22:1943-1949.

61 Heart Outcomes Prevention Evaluation (HOPE) Study Investigators. Effects of ramipril on cardiovascular and microvascular outcomes in people with diabetes mellitus: results of the HOPE study and MIRCO-HOPE substudy. Lancet. 2000;355:253-259.

62 Zandbergen AAM, Baggen MGA, Lamberts SWJ, et al. Effect of losartan on microalbuminuria in normotensive patients with type 2 diabetes mellitus: a randomized clinical trial. Ann Intern Med. 2003;139:90-96.

63 Buse JB, Ginsberg HN, Bakris GL, et al. Primary prevention of cardiovascular diseases in people with diabetes mellitus: a scientific statement from the American Heart Association and the American Diabetes Association.
Circulation. 2007;115:114-126.

64 ADVANCE Collaborative Group. Effects of a fixed combination of perindopril and indapamide on macrovascular and microvascular outcomes in patients with type 2 diabetes mellitus (the ADVANCE trial): a randomised controlled trial. Lancet. 2007;370:829-840.

65 Jamerson K, Bakris GL, Dahlöf B, et al; ACCOMPLISH Investigators. Exceptional early blood pressure control rates: the ACCOMPLISH trial. Blood Press. 2007;16:80-86.

66 Weber MA, Bakris GL, Dahlöf B, et al; ACCOMPLISH Investigators. Baseline characteristics in the Avoiding Cardiovascular Events Through Combination Therapy in Patients Living With Systolic Hypertension (ACCOMPLISH) trial: a hypertensive population at high cardiovascular risk. Blood Press. 2007;16:13-19.

67 O'Riordan M. ACCOMPLISH at 18 months: better bloodpressure control with single-tablet combination therapy. Heartwire. 2007. http://www.medscape.com/viewarticle/557061. Accessed September 27, 2007.

68 Iwai M, Li HS, Chen R, et al. Calcium channel blocker azelnipidine reduces glucose intolerance in diabetic mice via different mechanism than angiotensin receptor blocker olmestartan. J Pharmacol Exp Ther. 2006;319:1081-1087.

69 Savoia C, Touyz RM, Endemann DH, et al. Angiotensin receptor blocker added to previous antihypertensive agents on arteries in diabetic hypertensive patients. Hypertension. 2006;48:271-277. 